\title{
Safety of Oral Paracetamol - Analysis of Data from a Spontaneous Reporting System in Poland
}

\author{
Stanisław Han1, Ernest Kuchar ${ }^{2 *}$, Katarzyna Karłowicz-Bodalska1, Elżbieta \\ Kutycka ${ }^{3}$, Katarzyna Miśkiewicz ${ }^{2}$ and Aneta Nitsch-Osuch ${ }^{4}$ \\ ${ }^{1}$ Department of Industrial Pharmacy, Wroclaw Medical University, ${ }^{2}$ Department of Pediatric Infectious Diseases, Wroclaw \\ Medical University, ${ }^{3}$ Pharmacovigilance Department, PPF Hasco-Lek S.A. Wroclaw, ${ }^{4}$ Department of Family Medicine, Warsaw \\ Medical University, Warsaw, Poland
}

*For correspondence: Email: ernest.kuchar@gmail.com; Tel: +48717703156

Received: 16 October 2013

Revised accepted: 16 Macrh 2014

\begin{abstract}
Purpose: To determine the safety of oral coated paracetamol tablets $500 \mathrm{mg}$ and oral suspension 120 $\mathrm{mg} / 5 \mathrm{~mL}$ produced by Hasco-Lek Poland.

Methods: We analyzed sales volume and data obtained from the monitoring of spontaneous reports on the adverse effects of paracetamol collected in the period between November 2000 and June 2012.

Results: A total of 45,694 units of coated paracetamol tablets $(500 \mathrm{mg})$ and $6,048,289$ units of paracetamol oral suspension $(120 \mathrm{mg} / 5 \mathrm{~mL})$ were marketed during that period. There were 4 spontaneous reports of adverse effects.

Conclusion: Oral paracetamol is a safe medication rarely causing adverse effects but it is possible that the existing spontaneous monitoring system for adverse effects in Poland is not sensitive enough to detect all adverse effects, and needs improvement.
\end{abstract}

Keywords: Adverse reaction, NSAIDs, Pharmacovigillance, Pharmoepidemiology

\begin{abstract}
Tropical Journal of Pharmaceutical Research is indexed by Science Citation Index (SciSearch), Scopus, International Pharmaceutical Abstract, Chemical Abstracts, Embase, Index Copernicus, EBSCO, African Index Medicus, JournalSeek, Journal Citation Reports/Science Edition, Directory of Open Access Journals (DOAJ), African Journal Online, Bioline International, Open-J-Gate and Pharmacy Abstracts
\end{abstract}

\section{INTRODUCTION}

Paracetamol (acetaminophen), an active metabolite of phenacetin, is probably the most popular over-the-counter antipyretic and analgesic used in Poland. First introduced to the market in 1878 in Germany, it was quickly displaced by phenacetin and aspirin, but attracted new attention in the late 1940s when David Lester and Leon Greenberg found that paracetamol is a major acetanilide metabolite responsible for its analgesic properties and did not cause methemoglobinemia [1]. Squibb introduced paracetamol to the American pharmaceutical market in 1950 under the name Trigesic, then Apamid by Ames (Dome) in 1952 and Tylenol by McNeil in 1955 were introduced [2]. Now paracetamol is sold in almost every country worldwide with annual production exceeding 15,000 tons [3].

Paracetamol has analgesic and antipyretic properties comparable to those of aspirin and other non-steroid anti-inflammatory drugs (NSAIDs), but its peripheral anti-inflammatory activity is very limited. The action mechanism is not completely understood. The drug inhibits cyclooxygenase type 2 (COX-2) and its metabolites e.g. NAPQI and acts as an agonist of TRPA1-receptors in the spinal cord, which suppresses the pain transduction $[4,5]$. 
Paracetamol is commonly used for the relief of headaches and other minor pains and is a major active ingredient in numerous cold preparations.

Adverse effects of paracetamol are rare, but hypersensitivity including skin rash may occur. There have been reports of blood dyscrasias including, thrombocytopenia, neutropenia, pancytopenia, leukopenia and agranulocytosis, but these were not necessarily related to paracetamol $[6,7]$.

Post-marketing surveillance using tools such as data mining of spontaneous (passive) reports and the investigation of case reports to identify adverse drug reactions are very important in drug safety monitoring.

PPF HASCO-LEK S.A. manufactures medicinal products with paracetamol in the form of tablets (Paracetamol HASCO coated tablets $500 \mathrm{mg}$ ) and oral suspension (Paracetamol HASCO oral suspension $120 \mathrm{mg} / 5 \mathrm{ml}$ ). These medicinal products have been available on the Polish pharmaceutical market from November 2000. The manufacturer, as the Marketing Authorisation Holder (MAH), has a pharmacovigilance system at their disposal, which is based on current EU legislation. As part of the pharmacovigilance system, the MAH monitors spontaneous reporting i.e. adverse reaction reports submitted by healthcare professionals and patients or their carers and world literature. PPF HASCO-LEK SA cooperates closely with the Office for Registration of Medicinal Products, Medical Devices and Biocidal Products based in Warsaw, which is the National Monitoring Center in Poland. The monitoring actions aim to detect new drug adverse reactions and interactions as well as groups of patients with more frequently occurring adverse reactions.

Since no amount of pre-clinical and clinical data is sufficient to conclude the complete safety of a drug, it is necessary to report any adverse reaction to any pharmaceutical product to assess its safety to ensure patient health and this is the rationale of our study.

\section{METHODS}

This study identified new, unknown adverse effects of oral paracetamol and the analysed the safety of oral paracetamol produced by HascoLek, Poland (Paracetamol HASCO coated tablets $500 \mathrm{mg}$, Paracetamol HASCO oral suspension $120 \mathrm{mg} / 5 \mathrm{~mL}$ ).
We analyzed sales volume and data obtained from monitoring spontaneous reports on adverse effects of paracetamol HASCO coated tablets $500 \mathrm{mg}$ and paracetamol HASCO oral suspension $120 \mathrm{mg} / 5 \mathrm{~mL}$ collected by the manufacturer (PPF Hasco-Lek S.A. Wroclaw, Poland) and National Monitoring Center in Warsaw in the period between November 2000 and June 2012. The Polish system is based on written reports voluntary submitted by healthcare professionals.

\section{RESULTS}

A total of 45,694 units of paracetamol HASCO coated tablets $500 \mathrm{mg}$ and $6,048,289$ units of the oral suspension $(120 \mathrm{mg} / 5 \mathrm{~mL}$ ) produced by PPF HASCO-LEK S.A. Wroclaw, Poland were marketed during the period for which data were analyzed.

There were 4 spontaneous reports regarding these medications registered in Poland in the period analyzed:

1. A 67-year old woman received $500 \mathrm{mg}$ of paracetamol during post-operative pain management. A rash and itching were observed shortly afterwards.

2. A 21-month old boy weighing $12 \mathrm{~kg}$ developed generalised oedema of his soft tissues including his eyes, face and trunk (angioedema or Quincke's oedema) after the boy had been given paracetamol HASCO oral suspension $(7.5 \mathrm{~mL}$ of suspension i.e. $180 \mathrm{mg}$; $15 \mathrm{mg} / \mathrm{kg}$ ) for fever on the third day of chickenpox. The oedema responded well to steroid treatment.

3. A 58-year old woman received $2.0 \mathrm{~g}$ of paracetamol tablets during post-operative pain management. She complained of itching (without a rash).

4. A 28-year old woman presented with vomiting of blood (hematemesis) after she had taken $4.0 \mathrm{~g}$ of paracetamol tablets and $200 \mathrm{mg}$ of ketoprofen, an NSAID medication used for menstrual pain. She required hospitalisation. The adverse effect was most likely due to ketoprofen, but a causative relationship with paracetamol cannot be excluded completely.

\section{DISCUSSION}

Following the thalidomide tragedy in 1961, the WHO pursued measures aiming at the prompt detection and publication of information relating 
to unknown and poorly understood adverse effects of medications [8]. Therefore, in most countries worldwide, including Poland, drugrelated adverse reactions are monitored in order to increase the safety of pharmacological therapy. A new field of science, called pharmacovigilance, came into being [9]. As part of clinical trials preceding the launch of a drug, the most frequent adverse reactions are detected. Due to the number of subjects, very rare adverse effects with a frequency lower than $1: 10,000$ are hardly detectable. Paracetamol preparations used to treat common symptoms such as fever and pain are administered to hundreds millions of patients worldwide annually. With such extensive drug use, extremely rare adverse events, even those $<1$ per million, are unavoidable. The detection of these rare events is the issue addressed in these studies. For practical and financial reasons, the active surveillance of millions of patients is not feasible, thus pharmacovigilance is based on the analysis of spontaneous reports from healthcare professionals and consumers.

Paracetamol is a widely used agent with an excellent safety record and adverse effects are rare. However, in a few patients, skin and respiratory symptoms, immediate urticaria, angioedema, fixed drug reactions and allergic and non-allergic anaphylactic reactions have been reported in both children and adults in association with paracetamol administration [10-12]. Most reactions to paracetamol occur in patients with non-allergic hypersensitivity to NSAIDs. Alternatively, reactions may result from an allergic hypersensitivity to paracetamol, with tolerance of NSAIDs [10]. According to Paracetamol tablets Product Characteristics [13] hypersensitivity and anaphylactic reactions including skin rash may occur very rarely. These were observed in our report in cases 1,2 and 3 above. There have also been reports of blood dyscrasias including thrombocytopenia and agranulocystosis but these were not necessarily related to paracetamol.

The cases presented did not show any symptoms and signs of dyscrasias. Most reports of adverse reactions to paracetamol relate to overdosing with the drug due to a "narrow therapeutic window", i.e., a small difference between therapeutic and toxic doses. Chronic hepatic necrosis has been reported in a patient who took daily therapeutic doses of paracetamol for about a year and liver damage has been reported after daily ingestion of excessive amounts for shorter periods. Nephrotoxicity following therapeutic doses of paracetamol is uncommon, but capillary necrosis has been reported after prolonged administration [6].

Angioedema is a known but very rare adverse effect of paracetamol. Panchabhai et al [14] presented a 4-year old boy with a presumed viral infection who developed an allergic rash and angioedema in relation to paracetamol exposure. After he received 2 doses of syrup paracetamol (15 mg/kg/dose) within an hour, he developed oedema of the lips, along with massive dermal oedema, which initially involved the periorbital region and the face and later spread to the trunk and the limbs. Very similar symptoms were observed in our case. Bousseta et al [10] reported 25 cases of hypersensitivity in children after paracetamol treatment, including a single case of angiodema. An oral challenge to acetylsalicylic acid in this patient caused urticaria and angioedema. Oral challenges to paracetamol in the 24 other children studied were tolerated [10]. Adverse reactions temporally associated with paracetamol may result from reactions to other medications or the underlying conditions for which these medications have been prescribed. The diagnostic evaluation of suspected paracetamol hypersensitivity is further complicated by the lack of validated, skin or in vitro testing. Patient number 2 was treated for varicella, and the fact that the reaction occurred shortly after receiving the dose of paracetamol and that it happened on just a single occasion made the reaction acute angioedema. Nevertheless, the most common cause for a single isolated attack of angioedema is probably food allergy, idiopathic angioedema, acquired C1-inhibitor deficiency and infections, so varicella cannot be excluded as a primary cause [15]. Such a case has already been published [16].

Symptoms of paracetamol overdose in the first $24 \mathrm{~h}$ are pallor, nausea, vomiting, anorexia and abdominal pain. Liver damage may become apparent 12 to 48 hours after ingestion [13]. Case number 4, a 28-year old woman presented with vomiting of blood but had no further symptoms of liver damage, so those symptoms should be attributed to ketoprofen, a drug belonging to NSAIDs, well known for their gastrointestinal side effects. The reported symptoms of adverse reactions should thus be regarded as already known.

The analysis of adverse reactions associated with paracetamol-containing drugs such as Paracetamol HASCO coated tablets $500 \mathrm{mg}$ and Paracetamol HASCO oral suspension during their approx. 12-year market presence in Poland proves their safety. However, only four adverse reaction reports against an estimate of over 6 
million therapies may suggest low sensitivity of the existing monitoring system, particularly since the large electronic drug safety RxISK database (https://www.rxisk.org/Default.aspx) also including consumer reports contains 32,671 reports where paracetamol was the suspect drug covering 122,914 reactions of which 19,861 do not specify the patient's country. The database includes 3.9 million reports submitted to the FDA's MedWatch from 1st January 2004 to 31st March 2012. About a third of these reports came from outside the United States and paracetamolrelated reports accounted for $1.19 \%$ of all the reports.

The under-reporting of adverse effects may result from lack of awareness among medical professionals of the usefulness of any adverse drug-related data, including known and common adverse reactions.

\section{Limitation of the study}

The weakness of this paper is that it is based on passive adverse event reports and its strength is an approx. 12-year observation of the entire Polish population.

\section{CONCLUSION}

Forms of oral paracetamol are a safe medication rarely causing adverse effects. Only a few cases of known adverse effects were reported in the 12-year observation period after more than 6 million medication units were distributed. However, the scarce number of safety reports shows that the existing spontaneous monitoring system in Poland seems not to be sensitive enough to detect all adverse effects and needs improvement.

\section{REFERENCES}

1. Lester D, Greenberg $L A$, Carroll RP. The metabolic fate of acetanilid and other aniline derivatives: II. Major metabolites of acetanilid appearing in the blood. $J$ Pharmacol Exp Therapeut. 1947; 90(1): 68-75.

2. Sittig $M$ (Ed). Pharmaceutical Manufacturing Encyclopedia 2nd edn, Westwood, NJ:. Noyes Publications, 1988
3. Toxnet. Acetaminophen. [cited 2012 Oct 15]. Available from: from: http://toxnet.nlm.nih.gov/

4. Burkhard $H$, Cheremina $O$ and Brune K. 2008. Acetaminophen (paracetamol) is a selective cyclooxygenase-2 inhibitor in man. FASEB J. 2008;22:383-390.

5. Andersson DA, Gentry C, Alenmyr L, Killander D, Lewis SE, Andersson A, Bucher B, Galzi J-L, Sterner O, Bevan S, Högestätt ED, Zygmunt PM. TRPA1 mediates spinal antinociception induced by acetaminophen and the cannabinoid $\Delta(9)$ tetrahydrocannabiorcol. Nat Commun. 2011;2:551.

6. Calpol Infant Suspension. Summary of Product Characteristics last updated on the eMC: 04/04/2012 [cited 2012 Oct 15].Available from: http://www.medicines.org.uk/EMC/medicine/18986/S PC/Calpol+Infant+Suspension/\#UNDESIRABLE_EFF ECTS.

7. Sweetman SC (Ed). Martindale: The Complete Drug Reference. London, Pharmaceutical Press. Electronic version, 2012. [cited 2012 Oct 15]. Available from: www.medicinescomplete.com/mc/martindale/current/ 2679-

p.htm?q=paracetamol\&t=search\&ss=text\&p=5\#_hit

8. WHO 2002. The Importance of Pharmacovigilance. Safety Monitoring of medicinal products. World Health Organization. [cited 2012 Oct 15].Available from: $h$ ttp://apps. who.int/medicinedocs/en/d/Js4893e/

9. Edwards $B$, Tilson $H H$, West SL. Defining the competencies of those conducting pharmacovigilance. Pharmacoepidemiol Drug Saf. 2006; 15(3): 193-198.

10. Boussetta K, Ponvert C, Karila C, Bourgeois ML, Blic J, Scheinmann $P$. Hypersensitivity reactions to paracetamol in children: A study of 25 cases. Allergy. 2005; 60: 1174-1177.

11. Prabhu MM, Prabhu S, Mishra P, Palaian S. Cellulitis-like fixed drug eruption attributed to paracetamol (acetaminophen). Dermatol Online J. 2005; 11(3): 24.

12. Gowrinath K, Balachandran C. Anaphylactic reaction due to paracetamol. J Indian Med Assoc. 2004; 102: 223226.

13. Paracetamol Tablets $500 \mathrm{mg}$. Summary of Product Characteristics. Last updated on the eMC: 02/02/2011 [cited 2012 Oct 15]. Available from: http://www.medicines.org.uk/emc/medicine/24178/SP C\#UNDESIRABLE EFFECTS.

14. Panchabhai TS, Gogtay NJ, Bavdekar SB. Paracetamolinduced angioedema. Letter to the editor. Indian $\mathrm{J}$ Med Sci. 2008; 62: 420-422.

15. Kulthanan K, Jiamton $S$, Boochangkool $K$, Jongjarearnprasert K. Angioedema: clinical and etiological aspects. Clin Dev Immunol.. 2007, Article ID 26438. [cited 2012 Oct 15]. Available from: http://www.hindawi.com/journals/cdi/2007/026438/cta /

16. Dag H, Fenercioglu AK, Karatekin G. 2012. An Unusual Case Of Henoch-Schönlein Purpura Associated With Varicella Zoster Infection. Scientific Research and Essays. 2012; 7(26): 2284-2287. [cited 2012 Oct 15]. Available from: http://www.academicjournals.org/ SRE. 